\title{
A PRODUÇÃO TEXTUAL ESCRITA: JUNÇÃO E(M) AQUISIÇÃO
}

\author{
LÚCIA REGIANE LOPES-DAMASIO* \\ PATRÍCIA CELENE SENNA DA SILVA**
}

\begin{abstract}
RESUMO: Neste artigo, investigamos a constituição de tradições discursivas (TDs), na aquisição da escrita infantil, com base na ideia de que os mecanismos de junção do texto, em espaços determinados, são sintomáticos de TDs e vice-versa. Adotando um quadro teórico em que a descrição da escrita infantil é pautada na consideração conjunta de aspectos linguísticos e pragmático-discursivos, os resultados, alcançados a partir de uma análise de cunho qualitativo e quantitativo, mostram evidências de dois tipos de relações passíveis de serem estabelecidas entre esses mecanismos e as TDs focalizadas: (i) com as TDs narração, relato, argumentativa e explicativa, em que a repetibilidade dos espaços de junção preenchidos por mecanismos com acepção causal reafirma a hipótese que caracteriza o aspecto sintomático entre a TD que se constitui e a forma como os encadeamentos dessa natureza a constituem; e (ii) com as TDs cartão de Natal, injuntiva e pedido, em que o uso dos mecanismos de junção causal está relacionado à mescla de TDs, diretamente associada à parte do texto em que são inseridas TDs explicativas/argumentativas. Por isso, nessas TDs, a repetibilidade dos mecanismos de junção causal não pode ser o ponto de partida da análise, mas, sim, o seu papel pragmático-discursivo como matéria que constitui a composicionalidade da tradição textual.
\end{abstract}

Palavras-chave: escrita; tradição discursiva. mecanismos de junção.

ABSTRACT: In this paper, we shall investigate the establishment of discursive traditions (DTs) in children's writing acquisition, based on the idea that text junction mechanisms in determinate spaces are symptomatic of DTs and vice-versa. Following a theoretical framework in which children's writing acquisition is viewed under the consideration of both linguistic and discursive-pragmatic aspects, the results, obtained from a qualitative and quantitative analysis, provide evidence for two kinds of relationships which can be established between these mechanisms and the focused DTs: (i) with narrative, report, argumentative and explanatory DTs, in which the repeatability of junctions spaces filled by mechanisms with causal meaning reinforces the hypothesis outlining the symptomatic relation between the established DT and the means whereby such concatenations establish the DT; and (ii) with the Christmas card, injunction and request DTs, in which the usage of causal junction mechanisms is related to a mix of DTs, the latter being directly linked to the part of the text in which explanatory/ argumentative DTs are inserted. Therefore, in these DTs, the starting point of the analysis should not be the repeatability of causal junction mechanisms, but rather the pragmatic-discursive role as material for the compositionality of the textual tradition.

Keywords: writing. discursive tradition. join mechanisms.

"Universidade Estadual Paulista (UNESP), Assis, SP, Brasil. luciaregiane@bol.com.br

*** Instituto Federal de Mato Grosso (IFMT), Lucas do Rio Verde, MT, Brasil. senna_paty@ hotmail.com 


\section{INTRODUÇÃO}

Neste trabalho, investigamos a relação entre os mecanismos de junção ${ }^{1}$ e as tradições discursivas ${ }^{2}$ a que os textos pertencem e que esses mecanismos ajudam, concomitantemente, a constituir. Essa investigação se dá à luz da hipótese de Kabatek (2005) de que é possível depreender uma relação sintomática - para usar os termos do autor - entre mecanismos de junção e tradições discursivas. Essa "relação sintomática" significa que os mecanismos de junção usados num texto indiciam a natureza de sua tradição textual e vice-versa. Nessa perspectiva, o objetivo do trabalho é investigar as relações entre mecanismos de junção, com destaque para os causais, e tradições discursivas, no âmbito da constituição dessas tradições na aquisição da escrita.

Fundamental para este trabalho é a concepção de linguagem sócio-historicamente construída pelos sujeitos, que, por meio da interação cotidiana, apropriam-se e manipulam, organizam e ressignificam (d)os signos linguísticos, como modo sensível das transformações sociais (BAKHTIN \& VOLOCHINOV, 1995 [1929]). Nessa perspectiva, o sujeito-criança, na aquisição da escrita, lida, de forma particular, com o que lhe é novo; o modo de enunciação escrito. Para produzir seus textos escritos, costuma recorrer, portanto, àquilo que domina: ao modo de enunciação falado, em práticas orais, mas também à (sua) imagem de escrita, via modelos construídos na (sua) circulação por práticas letradas. Por isso, adotamos a noção de heterogeneidade da escrita, conforme Corrêa (2004), e, de acordo com ela, a pressuposição de um vínculo entre o oral/letrado e o falado/escrito.

Em diálogo com essa pressuposição, este trabalho concentra-se na questão: como a tradição discursiva contribui para o uso dos mecanismos de junção causais? e, inversamente; como esses mecanismos podem ser tomados como indícios de tradições discursivas? A hipótese, construída a partir do pressuposto de que a escolha dos juntores pode ser sintomática de tradições discursivas e mesclas de tradições discursivas, é a de que essas tradições são realizadas por meio do que o sujeito (re)conhece como o fixo e o lacunar do texto, neste trabalho, no modo escrito de enunciar.

\section{TRADIÇÃO DISCURSIVA E MECANISMOS DE JUNÇÃO: UMA PROPOSTA TEÓRICA PARA A ABORDAGEM DA ESCRITA INFANTIL}

A noção de tradição discursiva (TD, daqui em diante) surge na Linguística Histórica Românica, no âmbito da Filologia Pragmática alemã, na década de 80 . O

${ }^{1}$ Os mecanismos de junção, na perspectiva de Raible (2001), são quaisquer técnicas usadas para juntar porções textuais, podendo corresponder, categoricamente, a conjunções, advérbios, locuções preposicionais e zero (justaposição oracional). Focalizamos, principalmente, os juntores causais, cuja acepção efetiva-se à luz de relações discursivas, intrínsecas ao conhecimento de mundo dos participantes da interação (ZIV, 1993).

${ }^{2} \mathrm{O}$ conceito de tradição discursiva é tomado a partir dos trabalhos de Kabatek (2006, 2005, entre outros) e equivale, grosso modo, a modelos textuais, convencionalizados social e historicamente, que integram a memória de sujeitos enquanto membros de comunidades, podendo corresponder desde a gêneros discursivos e tipos textuais, até a construções linguísticas, como Era uma vez. 
termo Diskurstradition, proposto por Koch (1997) e adotado por outros linguistas alemães, como Oesterreicher e Kabatek, conceitua uma perspectiva histórica dos gêneros textuais (ASCHENBERG, 2002) que, com base no entendimento teórico coseriano de "língua concreta", tem sido, recentemente, usado também em pesquisas que se debruçam sobre fenômenos textuais em estado de língua sincrônico (cf. LONGHIN-THOMAZI, 2011a; LOPES-DAMASIO; SILVA, 2017, entre outros).

O conceito de TD fundamenta-se na teoria da linguagem coseriana, apoiada na ideia de que a linguagem não é produto, mas atividade, e na recuperação de um diálogo com o pensamento aristotélico de Humboldt. Enquanto atividade criadora, a linguagem não possui caráter "acabado", de "coisa feita", mas de um conjunto de "modos de fazer" (COSERIU, 1982), um sistema de produção que surge, apenas em partes, como produtos materializados linguisticamente, reconhecíveis como textos falados/escritos. ${ }^{3}$

Para a construção desse conceito, a concepção coseriana de língua, concreta e histórica, estende-se também ao recorte sincrônico (e torna-se oposta, portanto, à saussuriana). Nela, estão previstos três níveis do linguístico: (i) universal, em que a linguagem é considerada como atividade do falar, enquanto fato antropológico, representando aspectos universais genericamente humanos; (ii) histórico, em que é considerada como língua particular (português, espanhol etc.), incluindo suas variedades; e (iii) atual ou individual, como ato linguístico de um indivíduo numa situação determinada (COSERIU, 1980).

Nessa direção e a fim de refinar o conceito de TD, propomos algumas ressalvas quanto a esses níveis: (i) quanto ao nível histórico, reconhecemos que só existe história no nível atual, como ela só existe porque o ato linguístico nunca é individual; e (ii) quanto ao entendimento do nível atual, a que deve estar subjacente a ideia de sujeito da linguagem não como indivíduo - já que não é a singularidade factual, circunscrita a si mesma, que enuncia. O sujeito da linguagem é, pois, entendido como "individuação", referente à sua circulação dialógica. Só possui individualidade, portanto, em relação ao conceito de dialogia.

Os níveis estão presentes sempre que o sujeito, por meio da fala ou da escrita, dirige-se ao outro, com determinada intenção comunicativa. Percebemos, nessa ação, o nível universal, porque o sujeito que enuncia usa uma atividade comum aos homens; o nível histórico, porque, para enunciar, vale-se de um idioma historicamente atualizado; e o nível individual, porque enuncia numa situação concreta, única e particular, configurada por um entorno sócio-histórico-cultural. Nesse sentido, falar/escrever significa recorrer ao que tradicionalmente está instituído, do ponto de vista do idioma e das sucessivas atualizações de uma forma

${ }^{3}$ A noção de texto adotada segue a consideração da linguagem como acontecimento e não adequação, e a de processo de textualização, caracterizado como "acontecimento", não acabado senão na relação entre falante/ouvinte, autor/leitor. O sentido do texto é construído na experiência desse acontecimento, em que experiência deve ser tomada como retomada do já-experimentado, da memória do já-dito/escrito e do já-ouvido/lido, mas também como novidade da reatualização, em consonância com o conceito de TD. 
discursiva, e colaborar para a constituição dessa tradição, num diálogo complexo entre já-dito e novos projetos de dizer.

Segundo Koch (2008), nas TDs, a configuração assumida por uma intenção comunicativa pode não depender exclusivamente da tradição linguística e fixar-se, assim, em tradições do discurso. Destarte, o autor propõe a bipartição do nível histórico, acrescentando à história da língua, a história das TDs, e considerando que a segunda perpassa, transversalmente, a primeira: a partir de uma intenção, o ato comunicativo é filtrado pela organização linguística, na qual os signos são escolhidos, seguindo as regras sintáticas e a norma de uma língua/variedade particular, e, concomitantemente, pela ordem textual, responsável pela atualização de determinada TD.

Nessa linha, uma combinação de elementos, uma vez evocada, em uma situação concreta de interação verbal, produzirá uma repetição e sua concretização produzirá significado. Essa combinação aponta, ainda, para a composicionalidade das TDs, que pode ser: (i) paradigmática - refere-se à possibilidade de o texto agregar um conjunto de tradições, não necessariamente pertencentes a uma mesma área do saber; e (ii) sintagmática - num âmbito local, refere-se aos arranjos linguísticos realizados na linearidade da linguagem, a partir de escolhas paradigmáticas.

Kabatek (2005) afirma que uma TD pode se formar a partir de qualquer elemento significável, formal ou de conteúdo, cuja re-evocação estabelece um laço entre atualização e tradição. Assim, o autor propõe duas fases: a TD propriamente dita e a constelação discursiva evocada por ela. Nessa perspectiva, a TD adquire valor de signo, reconhecido por meio de outros signos que extrapolam os limites textuais. Ganha destaque, pois, o diálogo intrínseco entre TD, o já-dito, o que se diz e o(s) projeto(s) de dizer, sem com isso reduzir a novidade de cada acontecimento discursivo.

Num refinamento desse âmbito teórico, neste trabalho, a expressão tradição estará estreitamente relacionada à historicidade, no sentido de abarcar textos e fórmulas/expressões que caracterizam gêneros institucionalizados e atos de fala fundamentais; mas estará relacionada, da mesma forma, à experiência, no sentido do já sabido dessas relações. Por sua vez, a expressão discursiva estará relacionada não só à qualificação das tradições como linguísticas, a fim de abarcar todo tipo de tradição do falar/escrever, conforme Kabatek (2005), mas também à qualificação das tradições como acontecimento, que guarda, a cada nova realização, uma novidade que se dá no modo como se realiza aquela prática.

A partir desse entendimento do conceito de tradição discursiva, ${ }^{4}$ pressupomos que, antes de inserir-se na escrita, a criança domina várias TDs, especialmente as que se materializam na fala/oralidade, uma vez que o modo de

${ }^{4}$ Trata-se de propor um lugar próprio para a observação e tratamento teórico-metodológico da noção de TD, que abarca o conceito veiculado por Kabatek, guarda todas as relações possíveis com o conceito de gênero discursivo, mas preserva, ainda assim, a singularidade da noção. Essa singularidade, nesse lugar próprio de observação, garante a adequação de seu tratamento no âmbito de um estudo voltado à aquisição da escrita, em escopo, portanto, distinto do da linguística histórica, em que fora desenvolvido. 
enunciar que ela domina constitui as práticas mais recentes associadas àquele que está adquirindo. Sendo assim, seguindo os trabalhos de Abaurre et al. (2002, p. 16-17), nas operações iniciais da escrita infantil, o que normalmente é entendido como erro - a partir do modelo de gramática do adulto -, corresponderá, neste trabalho, a indícios de um processo de representação escrita da linguagem que ganharão estatuto de registro dos momentos em que a criança deixa evidências de sua manipulação da linguagem, (re)construindo essa relação por meio de sua inserção em práticas de escrita e leitura.

Segundo Abaurre et al. (2002, p. 22), a aquisição da escrita é um momento particular de um processo mais geral de aquisição da linguagem, no qual, ao reconstruir sua relação com a linguagem, o sujeito toma diferentes caminhos para relacionar as manifestações orais/faladas e letradas/escritas de uma mesma língua. Desse ponto de vista, a posição de sujeito seria também, essencialmente, histórica, regulada pela linguagem - historicamente constituída - e pela atuação do outro, que o interpela, o afeta e é afetado por esse processo. O outro deve ser considerado, em sua dimensão física e empírica, enquanto instância de representação do funcionamento convencional da linguagem, na escrita, a partir de representações que o sujeito faz sobre ele. Para Abaurre et al. (2002), o lugar desse processo é a interlocução entre sujeitos que se constituem em outros para seus interlocutores, constituindo-os também como sujeitos. ${ }^{5}$ O sujeito, considerado como individuação dialógica, é, portanto, constituído em sua relação com a linguagem, concebida como lugar de interação, interlocução e tomada como atividade/trabalho. A relação sujeito/linguagem é vista como processo não-cumulativo, com (re)elaborações, (re)estruturações, variações e, mesmo, idiossincrasias que podem ser tomadas como indícios dos movimentos dos sujeitos em constituição. A aquisição da escrita, assim, é vista como processo complexo de contínua, mas não linear, mudança na relação sujeito/linguagem, intermediado pelo outro.

A busca do sujeito-criança pelo funcionamento convencional do modo escrito de enunciação é controlada e organizada pela linguagem que se desvenda, em diferentes momentos e espaços, nas práticas sócio-histórico-culturais vivenciadas por esse sujeito, seja por meio da fala seja por meio da escrita (CAPRISTANO, 2007, p. 71). Assim, suas hipóteses incidem sobre possibilidades abertas pelo sistema da língua e pelas TDs.

As características textuais de diferentes TDs podem determinar a utilização de tal ou qual forma de junção, por predominância, alternância ou exclusão de técnicas específicas. No âmbito da realização da linguagem como acontecimento,

${ }^{5}$ No diálogo entre criança e adulto letrado, encontram-se indícios, segundo Abaurre et al. (2002), de que ambos se movimentam, já que o que o adulto faz e diz repercute no que a criança faz e diz e vice-versa. O adulto letrado constitui-se num outro que confronta o sujeito-criança com a ideia de que a escrita veicula sentidos e não é simples sequência de letras desenhadas ao acaso, o que desencadeia, nesse sujeito, a busca por esses sentidos. A criança, também se constituindo num outro para o sujeito-adulto letrado, confronta-o com sua leitura. Ao não utilizar as convenções (pré) estabelecidas pelo sistema, a criança força o adulto a rever sua leitura e a aceitar o que é oferecido por ela como um sentido (dentre outros). 
tal como adiantamos, "específico" quer dizer, ao mesmo tempo, "geral" e "particular", ou seja, inscrito na história (VEYNE, 1971, p. 48). A relação entre os mecanismos de junção e o específico de Veyne depende de uma segunda relação, nela subjacente, entre mecanismos de junção e espaço de junção, o que permite observar as técnicas de junção sem perder de vista o ponto em que elas ocorrem. Trata-se de uma observação do contexto linguístico, em que se vincula a ocorrência de uma TD à dimensão sintática da língua. No entanto, ao mesmo tempo, trata-se de uma observação do contexto enunciativo, no qual a sintaxe é vista como dimensão de contato entre a virtualidade do sistema e a sua realização. Assim entendida, a dimensão sintática permite observar as junções não apenas como recursos formais da língua, mas, também, como memória de realizações já feitas. Nesse sentido, a própria junção, tomada como procedimento formal, integra-se, portanto, à língua e ao texto, obedecendo, neste último, a restrições de outra ordem, não simplesmente formais, mas histórico-discursivas.

Assim, as junções e os espaços de junção podem ser vistos como recursos textuais de verticalização no tempo, operando, retroativamente, com certas regularidades linguísticas, mas também, em seu retorno, construindo uma atualidade de sentido e antecipando, prospectivamente, outras possibilidades de ocorrência. O espaço de junção não se restringe, portanto, à descrição do contexto linguístico, mas marca a especificidade de que fala Veyne (o particular e o geral da singularidade histórica).

Para a análise linguística dos mecanismos de junção (MJs, daqui em diante), em espaços de junção determinados, consideramos a conjugação de dois eixos, com diferentes graus de complexidade: um sintático (vertical) e outro semântico (horizontal). No eixo sintático, partimos da parataxe até a hipotaxe, ${ }^{6}$ e, no horizontal, consideramos as relações semânticas expressas pelos juntores, focalizando, mais especificamente, a noção de causalidade. De acordo com esse esquema, uma mesma relação semântica encontra possibilidades variadas de expressão tática, o que o distancia da tradição gramatical e o fundamenta num modelo funcionalista de linguagem em que a relação entre as orações está pautada na não discretude dos processos e sentidos da junção.

Para abordar a especificidade do particular e do geral da singularidade histórica, nos espaços de junção, as condições de produção somam-se às propriedades constitutivas das TDs, em seus diferentes tipos, como presentes na constituição dos fatos discursivos. Somam-se, portanto, como fator determinante para as características de uma tradição, ligadas às práticas sociais de onde provêm, não como produto escrito, avaliado unicamente segundo certos parâmetros como: mais ou menos formal, mais ou menos planejado, mais ou menos simétrico etc. Deixamos de ligar, assim, a tradição apenas à experiência. Ao pensar em TD, no entanto, entendemos que esse encontro não é só experiência (o já sabido dessas relações), mas é também acontecimento (em que a novidade se dá no modo como

${ }^{6}$ Se as orações são livres e constituem cada uma um todo funcional, a construção é paratática (ordem fixa); se uma oração domina/modifica a outra, é dominante e, portanto, nuclear, enquanto a outra é dependente e, portanto, modificadora, a construção é hipotática (há dependência). 
se realiza aquela prática). Em outras palavras, o que está "preparado" para uma situação também fala como "experiência", mas nunca fala só pela "experiência" nem só pelo "acontecimento", mas em função do encontro entre uma e outro. Ao recusar a ligação da tradição apenas à experiência e propor associá-la ao acontecimento, entendido como questão própria da experiência, no sentido da novidade que toda reapresentação da experiência traz e no sentido de retomada do já-experimentado, criamos um espaço de observação próprio para as TDs em relação à heterogeneidade da escrita: $\mathrm{a} \mathrm{TD}$, considerada como matéria e produto da linguagem, entendida como experiência (memória) e como acontecimento (produto discursivo). ${ }^{7}$

\section{MATERIAL E METODOLOGIA}

A partir desse ponto de observação das TDs, a investigação de sua constituição, a partir da hipótese de que os MJs do texto, em espaços determinados, são sintomáticos de TDs e vice-versa, será realizada, via análise de natureza quantitativo-qualitativa, de uma amostra constituída de 100 textos, extraídos do Banco de Dados que subsidia as pesquisas do Grupo de Estudos da Linguagem (GPEL/CNPq), no interior do qual este trabalho foi desenvolvido. Os textos que constituem o corpus aqui investigado são parte do material coletado por Capristano, em escola pública de S. J. do Rio Preto-SP, quinzenalmente, de 2001 a 2004 (ao longo das antigas $1^{\mathrm{a}}$ a $4^{\mathrm{a}}$ séries do Ensino Fundamental). Trata-se de uma amostra longitudinal porque os mesmos alunos foram acompanhados no período em questão. Para o presente trabalho, foram escolhidos, aleatoriamente, 25 textos de cada uma dessas séries.

Para evidenciar a relação entre MJs e TDs, apresentamos Juntogramas com a síntese do funcionamento linguístico desses processos, em textos representativos das tradições analisadas. Os Juntogramas são gráficos bidimensionais que permitem uma visualização dinâmica do mapeamento das experiências juntivas realizadas, no texto, indicando os mecanismos específicos, sua frequência de uso e distribuição. Em sua dimensão superior, são expostos os graus de interdependência tática - parataxe e hipotaxe - e, na inferior, as relações semânticas - em uma escala de complexidade cognitiva crescente (cf. LOPES-DAMASIO, 2011). Cada Juntograma sistematiza a análise de um texto, na rede de tradições que o corpus do estudo comporta.

$\mathrm{Na}$ seção seguinte, apresentamos a descrição analítica de cinco textos cujo funcionamento dos MJs, de um modo geral, e dos causais, especificamente, revela-se sintomático de (mesclas de) TDs. ${ }^{8}$ Em outras palavras, os Juntogramas, produzidos a partir da análise quantitativoqualitativa dos MJs desses textos, sintetizam funcionamentos linguísticos dos

${ }^{7}$ Essa divisão "metodológica" não esconde que a TD se realiza no encontro entre experiência e acontecimento.

${ }^{8}$ Em cada texto, estarão destacados, em negrito, os MJs, e será inserida a notação "Ø” para identificar a justaposição, em que o mecanismo é zero. 
processos juntivos constatados em todo o corpus, em intrínseca relação com as tradições que os constituem, e, consequentemente, sinalizam resultados à luz dos objetivos deste trabalho. Portanto, os textos apresentados são considerados representativos porque ilustram a funcionalidade da relação entre TD e os espaços juntivos de acordo com o fator de repetibilidade e também de acordo com a singularidade que indicia escolhas dos sujeitos no contexto de aquisição da escrita.

\section{RELAÇÕES SINTOMÁTICAS ENTRE MECANISMOS DE JUNÇÃO E TRADIÇÕES DISCURSIVAS}

Para a produção do Texto (1), a pesquisadora perguntou às crianças se conheciam a história d'Os três porquinhos e, mediante respostas afirmativas, pediu a uma delas que a contasse para a classe. Depois, leu-lhes o diário do lobo, outra versão da história, e pediu que escrevessem uma das versões ou criassem uma nova:

Texto (1)

O DIÁRIO DO LOBO

A VERDADEIRA HISTÓRIA DOS 3 PORQUINHOS

ERA UMA VEZ UM LOBO EU ESTOU FAZENDO O BOLO DA MINHA QUERIDA VOVOZINHA E ESTAVA PRECISANDO DE UMA XÍCARA DE AÇÚCAR E FUI PEDIR PARA O MEU VIZINHO AÇÚCAR PARA MEU VIZINHO PORCO Ø ACREDITA QUE ELE CONSTRUIU UMA CASA DE PALHA Ø EU FUI LÁ PARA PEDIR AÇÚCAR Ø O PORCO ME DISSE VAI EMBORA LOBO E SENTI UM ESPIRRO E ATIM E A CASA DERRUBOU E O PORCO LÁ NO CHÃO MORTO DA SILVA Ø EU FUI NA CASA DO IRMÃO DO PORCO ERA UM POUCO MAIS ESPERTO Ø FEZ UMA CASA DE LENHA E PEDI AÇÚCAR PARA ELE Ø ELE DISSE NÃO E ESPIRREI ATIM E A CASA DESMORONOU E O PORCO MORREU. $\varnothing$ EU REPETI O PRATO $\varnothing$ EU FUI NO OUTRO PORCO $\varnothing$ EU ESPIRRANDO Ø ELE FALAVA E FIQUEI BRAVO E A POLÍCIA ME PRENDEU Ø ME DÁ UMA XÍCARA DE AÇÚCAR FIM. [01/06/06]

O Texto (1) é uma TD narrativa, porque nele uma história é contada e há personagens atuando em espaço e tempo determinados. De acordo com a sua composicionalidade com a tradição dos contos de fada, a TD narrativa pode apresentar personagens animais com atributos humanos, como ocorre em (1). Outras características dessa tradição é a presença de título " $O$ diário do lobo/A verdadeira história dos 3 porquinhos", de diálogos e da sequencialidade temporal. Somamos a esse quadro, ainda, a ocorrência dos usos de Era uma vez e de fim que caracterizam, por si sós, TDs que constituem composicionalmente a TD narrativa, 
enquanto indícios da circulação do sujeito pelo universo de histórias fictícias, como as fábulas e os contos de fada.

Quanto à marcação do diálogo, para narrar a sua história, o sujeito insere, sem anunciar, o discurso direto, no final do texto "me dá uma xícara de açúcar?" e usa essa estratégia para marcar o diálogo com o seu possível leitor "acredita que ele construiu uma casa de palha?". Essa forma de interatividade demonstra a heterogeneidade da escrita, o trânsito desse sujeito por diferentes modos de enunciação da língua, falado e escrito, bem como a imagem que a criança faz dessa tradição textual.

Para as relações entre a TD narrativa e os MJs, apresentamos o Juntograma (1):

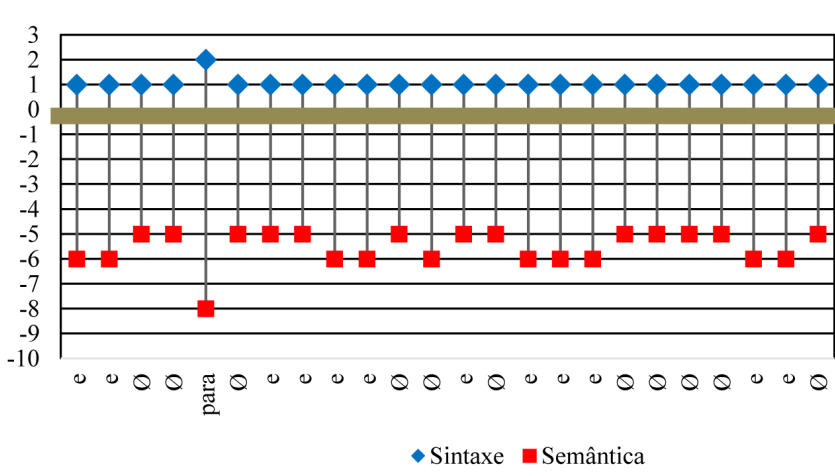

\begin{tabular}{|l|}
\hline Legenda \\
Sintaxe \\
$1=$ parataxe \\
$2=$ hipotaxe \\
Semântica \\
$-1=$ adição \\
$-2=$ alternância \\
$-3=$ modo \\
$-4=$ comparação \\
$-5=$ tempo \\
$-6=$ causa \\
$-7=$ condição \\
$-8=$ finalidade \\
$-9=$ contraste \\
$-10=$ concessão \\
\end{tabular}

Juntograma 1: Mapeamento dos MJs na TD narrativa - Texto (1) [01/06/06].

O Juntograma (1) mostra a predominância dos MJs e e $\varnothing$, com acepções temporais e causais na parataxe. Segundo Costa e Sousa (2010), a causalidade é fundamental para o texto narrativo, devido à sua organização: inicia-se a história com uma situação equilibrada, que, por alguma força, é desequilibrada. Há transformações e, por fim, o equilíbrio é reestabelecido pelas ações de um herói, motivadas por seus objetivos. A causalidade encadeia-se, pois, com a sucessão de eventos e a justificativa das ações das personagens, conforme Juntograma 1 e o seguinte trecho do Texto (1):

\section{(1) O PORCO ME DISSE VAI EMBORA LOBO E SENTI UM ESPIRRO E ATIM E A CASA DERRUBOU E O PORCO LÁ NO CHÃO MORTO DA SILVA}

Em (1), a sequencialidade temporal é base da relação de posterioridade entre os eventos, em "o porco me disse vai embora logo e senti um espirro e atim", e implica a relação causal entre eles, numa ordenação icônica: espirrar é a causa de ter derrubado a casa (efeito) e a casa ter caído é a causa de o porco estar morto da silva (efeito). Portanto, a ordem das orações é fixa e obedece à sequencialidade causa $>$ efeito. 
Nesses contextos, o uso frequente de (i) justaposição e $e$; e (ii) recursividade, conforme movimento de projeção e retroação, esquematizado em 1, demonstra a complexidade das construções paratáticas (cf. LONGHIN-THOMAZI, 2011):

\begin{tabular}{|l|l|r|}
\hline CAUSA & \multicolumn{1}{l}{ EFEITO } & \\
\hline \multirow{3}{*}{ senti um espirro e atim } & CAUSA & EFEITO \\
\cline { 2 - 3 } & e a casa derrubo & $\begin{array}{r}\text { e o porco lá no } \\
\text { chão morto da silva. }\end{array}$
\end{tabular}

Esquema 1: Recursividade na construção causal paratática.

Quanto às construções causais, sete são codificadas pelo padrão causa/ efeito, duas são do tipo asserção/conclusão e uma, asserção/explicação. A análise detalhada dos complexos causais permite a identificação da tradição explicativa, como em (2):

(2) EU FUI NA CASA DO IRMÃO DO PORCO ERA UM POUCO MAIS ESPERTO Ø FEZ UMA CASA DE LENHA E PEDI AÇÚCAR PARA ELE

O sujeito prossegue com a narrativa "Eu fui na casa do irmão do porco" e, nesse contexto, insere uma descrição, em "era um pouco mais esperto", que se caracteriza a partir de uma avaliação subjetiva feita a respeito da personagem com base naquilo que realiza " $f e z$ uma casa de lenha". A avaliação, assertivamente realizada, é explicada no segundo segmento do complexo causal, por um fato no mundo imaginário. Pragmaticamente, há uma relação epistêmica entre a conclusão ou avaliação/julgamento e as suas causas ou motivações. Nessa relação causal do tipo asserção/explicação, fica codificada, portanto, a tradição descritiva que constitui, composicionalmente, a narrativa, de acordo com o que temos chamado de mescla de TDs.

A codificação da causalidade do tipo asserção/conclusão é usada, no encerramento do texto, no trecho "e a policia me prendeo", que traz a conclusão numa relação causal marcada entre esse trecho e todos os demais eventos narrados. ${ }^{9}$

Para a produção do Texto (2), as crianças escolheram o tema Dia Internacional da Mulher, dentre um conjunto de temas sugeridos. A análise do material produzido

${ }^{9}$ Um tipo específico de tradição, no âmbito do narrar, é identificado como TD relato, com base na repetibilidade da intenção comunicativa do sujeito de contar uma história que aconteceu especificamente com ele. A TD relato está relacionada à apresentação de informações sobre um acontecimento, envolvendo, com frequência, a descrição. Nela, observam-se elementos básicos da narrativa - sequência de fatos, personagens, predomínio do tempo passado, espaço e narrador protagonista, sendo assim, os verbos são empregados em primeira pessoa. Há, portanto, na TD relato, uma mescla com as tradições narrativa e descritiva que lhe são constitutivas. Dessa forma, essa TD também experimenta a causalidade como uma acepção fundamental para o desenvolvimento textual, devido à sua organização; para relatar, o sujeito encadeia construções causais - especialmente do tipo causa/efeito -, seguindo a ordem temporal dos fatos. É recorrente, também, a apresentação, no final do texto, de um complexo asserção/conclusão, articulando a TD "e nós vivemos felizes para sempre", pertinente à composicionalidade da TD desenvolvida, num esquema conclusivo. 
mostra que os sujeitos desenvolveram, predominantemente, textos pertencentes à TD argumentativa, como exemplifica (2):

Texto (2)

E tão dificil entender uma mulher

quando escuta falar isso ela deixa marcado

com um beijo

E oferece seu ombro como reconcilho, e

pensa com o coração e fez com a emoção.

E todo o seu trabalho e reconpensado

e é muito importante o trabalho delas.

Como dentista. Doutoras, enfermeira fa

chineira, medica e etc

mas a principal é a professora $\varnothing$

sen ela nós não teriamos aprendido isso

que nós aprendemos, e sen ela nos não iriamos

aprender.

Por isso a mulher e tão importante

no mundo. [04/42/02]

A essência dessa TD vai além de trazer informações sobre o tema discutido. Segundo Guimarães (2001) e Campos (2005), uma das consequências da organização argumentativa do texto é a construção de uma "representação da intencionalidade do sujeito", entendida como apenas aparente. Na argumentação, uma estrutura encadeada por um MJ, do tipo $x$ MJ $y$, produz efeitos de referencialidade, de modo que as partes encadeadas são tomadas pelos sujeitos como procedimentos para "persuadir o interlocutor/leitor", interpretadas como uma razão que conduz a determinada conclusão. Apesar desses efeitos que apontam um "mundo lá fora" e que associam a argumentação a um conjunto de intenções persuasivas, a sua constituição está/é dependente do encadeamento. Os efeitos de referencialidade da argumentação dependem exclusivamente, portanto, da estrutura argumentativa codificada linguisticamente. ${ }^{10}$ A fala e a escrita da criança evidenciam que a argumentação é, desse modo, uma "ilusão" promovida no encadeamento, que gera efeitos de sentido, de referencialidade e de intencionalidade, que podem ser perscrutados na linguagem da criança, mesmo que seus enunciados constituam-se, muitas vezes, de incorporações de argumentos do adulto.

O Juntograma 2 mostra os MJs na constituição da TD argumentativa:

${ }^{10}$ Desse ponto de vista, em diálogo com Ducrot (1977), a argumentação dissocia-se da retórica, como numa concepção tradicional que a define como quase-demonstração, e associa-se à língua. 


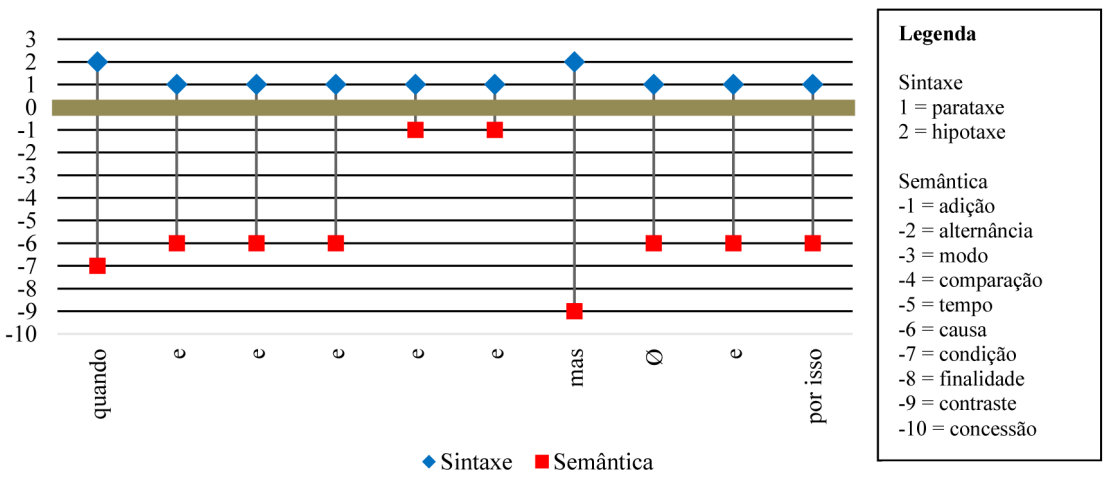

Juntograma 2: Mapeamento dos MJs na TD argumentativa - Texto (2) [04/42/02].

O Juntograma (2) evidencia os encadeamentos que constroem a orientação argumentativa dos enunciados e a predominância de MJs com acepções mais abstratas, como: causa, nos usos de e, justaposição e do prototípico por isso; condição, no uso de quando (E tão dificil entender uma mulher quando/se escuta falar isso ela deixa marcado com um beijo); e contraste, com mas (mas a principal é a professora).

O sujeito inicia seu texto com a asserção de que é tão difícil entender uma mulher e, por meio da recursividade de construções causais do tipo asserção/ explicação, que constituem três argumentos, encadeia explicações para essa afirmação - porque oferece seu ombro como reconcílio, porque pensa com o coração e porque faz com a emoção. Seguindo, apresenta mais um argumento, o de que o trabalho da mulher é importante, e, para defendê-lo, elenca algumas profissões, até afirmar que ser professor é a mais importante. Para o efeito de convencimento do leitor, o sujeito apresenta dois argumentos que se resumem em um; sem professor as pessoas não iriam aprender:

(3) $[. .$.$] mas a principal é a professora \varnothing$ sen ela nós não teriamos aprendido isso que nós aprendemos, e sen ela nos não iriamos aprender.

Num esquema paratático, o segundo e o terceiro segmentos oracionais, introduzidos, respectivamente, pela justaposição e por $e$, explicam, com base na opinião/avaliação do sujeito, a asserção realizada no primeiro segmento, configurando, portanto, recursivamente, o par asserção/explicação.

Apenas no final, na configuração da conclusão, com forte papel argumentativo, o sujeito apresenta o argumento principal de seu texto, encadeado por por isso; o de que a mulher é importante no mundo. Os encadeamentos constroem, assim, a orientação argumentativa dos enunciados, na língua, materializando a tradição argumentativa, por meio de um forte apoio na relação causal.

A proposta de produção (3) solicitou que cada uma das crianças fizesse um cartão de Natal para as fonoaudiólogas que haviam ministrado palestras na escola. 
Texto (3)

$\underline{\text { SÃO JOSE DO RIO PRETO }}$

06/12/2001. nome:

Querida e cara cris estou escrevendo

este cartão porque você mandou

um para agente e tambem porque

é dia de natal é por isso que estou

mandando este cartão para você

e para as outras amigas tamben $\varnothing$

é tudo o que eu tenho para

vocês $\varnothing$ espero que vocês tenha gostado.

asinado [desenho] [01/14/20]

Os sujeitos desenvolveram textos constituídos por uma mescla entre as TDs cartão de Natal e explicativa. No texto (3), a reprodução da estrutura da TD cartão, configura-se pelos aspectos formais dados à produção: desenhos realizados com motivos natalinos, configuração da capa do cartão, disposição do texto na página, dividida ao meio. Além disso, apresenta, estruturalmente, vocativo (Querida e cara cris...), assinatura, data (06/12/2001) e uma despedida (é tudo o que eu tenho para vocês espero que vocês tenha gostado). A finalidade, entretanto, dessa tradição é o oferecimento de uma breve mensagem, normalmente no miolo do texto, com o intuito de manifestar, a uma pessoa ou a um grupo, sentimentos de felicitações.

A TD explicativa toma espaço no miolo da TD cartão de Natal, conforme princípio de composicionalidade, substituindo a "mensagem natalina" e, consequentemente, a finalidade desse texto. A TD explicativa promove esclarecimentos, quer seja de informações expostas no texto, quer seja de atitudes tomadas pelo sujeito ou por outrem. A intencionalidade é, portanto, fazer com que o leitor adquira um conhecimento que até então não tinha, via informações que são acrescentadas por meio da exposição de causas e consequências de determinadas atitudes ou características. Em (3), o pequeno texto, inserido no espaço da mensagem, objetiva expor os fatos que levaram o sujeito a produzir o "cartão para C. e suas amigas".

No Juntograma (3), destacamos os MJs que ocorrem no Texto (3): 


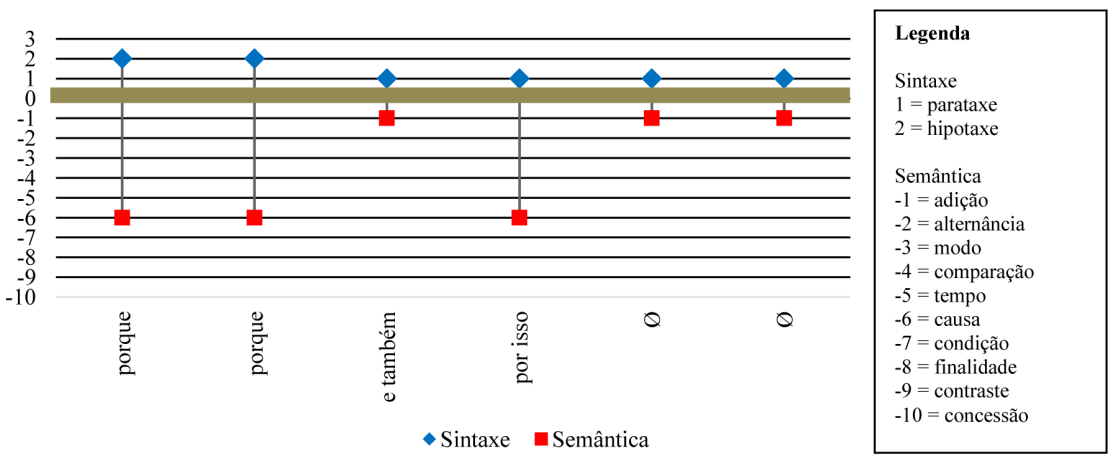

Juntograma 3: Mapeamento dos MJs na TD cartão de Natal/explicativa - Texto (3) [01/14/20].

O Juntograma ilustra ocorrências causais de porque e por isso, além de $e$ também e justaposições, com acepção aditiva, especificamente nos encadeamentos da despedida da TD cartão de Natal. O sujeito utiliza o padrão efeito/causa, apresentando duas causas para o efeito "estou escrevendo este cartão", ligadas por e também:

(4) estou escrevendo este cartão porque você mandou um para agente e tambem porque é dia de natal é por isso que estou mandando este cartão para você

Dessa forma, os MJs porque introduzem informações no texto, marcando causalidade entre eventos do mundo real, no qual é comum retribuir cartões, especialmente na época de Natal, e constituem a tradição explicativa, completada, ainda, em recursividade, pela inserção de uma conclusão, com o uso de por isso. A recursividade, no caso do par asserção/conclusão, constitui-se tanto pela repetição do conteúdo, quanto pelo caráter anafórico do juntor por isso.

A maneira como esse sujeito (a exemplo de outros), em AE, produz seu texto, sinaliza a mescla não convencional de TDs, ${ }^{11}$ já que geralmente não se utiliza o espaço da mensagem de um cartão de Natal para explicar os motivos que levaram a escrevê-lo. Essa mescla é indiciada pelo aspecto sintomático dos MJs, evidenciado na alteração do padrão semântico das técnicas de junção, de causa para adição, respectivamente, na TD explicativa e na porção de despedida da TD cartão de Natal.

Para a produção do Texto (4), a pesquisadora distribuiu um panfleto educativo sobre a Dengue, pediu para que as crianças lessem-no com atenção. Logo depois, recolheu-o e solicitou que escrevessem sobre o assunto:

${ }^{11}$ Trata-se de um desvio padrão, ou seja, um uso que, embora se repita nos textos, caracteriza um dado que indicia a relação não óbvia construída entre sujeito e linguagem. 
Texto (4)

[desenho]

NÃO DEIXE AS BOCA DAS GARRAFAS PROALTO ø AS

TANPAS NO LIXO ø PÕE NOS CACOS DE VRIDOS NO

LIXO SI JOGA CACO DE VRID NO CHANÃO AS

CRIANÇAS BODE CORTAR E MACHUCAR INTÃO

PUFAVOR NÃO JOGA CACO DE VRIDO NO

CHÃO Ø TEM MUITO CRINAÇA QUE JA MACHUCO [01/08/23]

O sujeito elenca uma série de instruções, numa TD injuntiva, cuja finalidade é orientar o leitor, construída em formato de listagem. A característica mais evidente dessa TD é o uso dos verbos no imperativo, ${ }^{12}$ indicando o que leitor deve fazer (põe nos cacos de vidros no lixo), o que não deve fazer (não joga caco de vrido no chão) e, muitas vezes, o modo como deve fazer (não deixe as bocas das garrafas proalto). Para isso, lança mão de orações paratáticas justapostas: (1) não deixar as bocas das garrafas viradas para o alto; (2) deixar as tampas no lixo; e (3) colocar os cacos de vidro no lixo. Numa lista de recomendações, o sujeito desenvolve seu texto a partir da inserção de informações novas, por justaposição, em cada membro do constructo paratático. Embora possa haver uma alteração na sequência de recomendações - o que caracteriza a construção como simétrica -, há, pragmaticamente, entre elas, um crescente de relevância que só pode ser depreendido no próprio texto: a terceira oração justaposta põe os cacos de vidro no lixo assume papel central para o desenvolvimento textual que segue: as crianças podem se cortar, se os cacos de vidro forem jogados no chão. ${ }^{13}$

Na continuidade, a TD injuntiva é seguida da argumentativa:

(5) PÕE NOS CACOS DE VRIDOS NO LIXO SI JOGA CACO DE VRID NO CHANÃO AS CRIANÇAS BODE CORTAR E MACHUCAR INTÃO PUFAVOR NÃO JOGA CACO DE VRIDO NO CHÃO Ø TEM MUITO CRINAÇA QUE JA MACHUCO

Após o trecho injuntivo "poe nos cacos de vridos no lixo", o sujeito, na representação da intencionalidade persuasiva, insere trechos argumentativos, encadeados pela condicionalidade "si joga caco de vrid no chanão...", e por então, seguido pela expressão clamativa por favor "intão purfavor não joga caco de vrido no chão...”. A orientação argumentativa desses enunciados está também relacionada à repetição do conteúdo que o sujeito avalia como mais importante $(o$ fato de as crianças poderem se machucar se os cacos de vidro forem jogados no chão).

${ }^{12}$ Característico dessa TD em textos cuja escrita esteja convencionalizada. Nos analisados aqui, produzidos na fase de aquisição da escrita, os sujeitos, frequentemente, empregam o modo indicativo.

${ }^{13}$ Esse desenvolvimento ilustra um contexto em que o sujeito oscila entre o que deveria escrever, respeitando o pedido feito na proposta, e o que efetivamente deseja escrever. 
No Juntograma (4), destacamos os MJs que ocorrem no Texto (4):

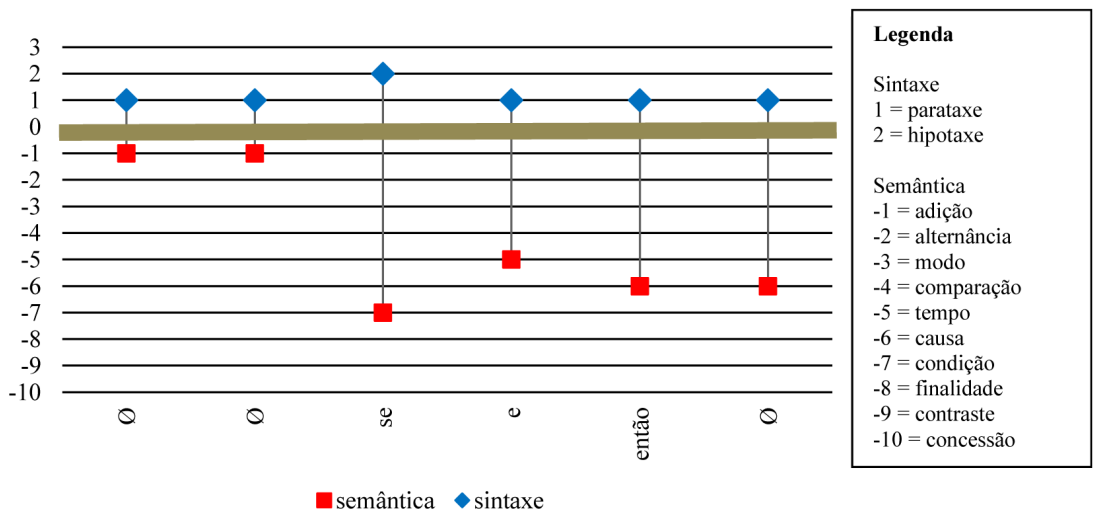

Juntograma 4: Mapeamento dos MJs na TD injuntiva - Texto (4) [01/08/23].

O Juntograma mostra duas ocorrências subsequentes de justaposição aditiva, funcionando na inserção da sequência injuntiva que inicia o texto; o MJ condicional $s e$, no âmbito da argumentação; uma ocorrência de $e$ aditivo, funcionando na inserção de um novo enunciado injuntivo, seguido pelos enunciados introduzidos por então e justaposição, relacionados à mescla da injunção com a argumentação, no final do texto:

\section{(6) SI JOGA CACO DE VRID NO CHANÃO AS CRIANÇAS BODE CORTAR E MACHUCAR INTÃO PUFAVOR NÃO JOGA CACO DE VRIDO NO CHÃO Ø TEM MUITO CRINAÇA QUE JA MACHUCO}

A causalidade é identificada em conclusões articuladas pelo MJ então, numa construção hipotética - si joga caco de vrid no chanão as ciranças bode cortar e machucar então não joga caco de vrido no chão, e, em seguida, pela justaposição, no par asserção/conclusão "não joga caco de vrido no chão tem muito criança que já machuco", caracterizando a mescla entre as TDs injuntiva e argumentativa, marcada nos espaços de junção com acepção causal, ou seja, a relação entre a causalidade e o ponto do texto em que o sujeito justifica uma instrução/ordem, a fim de, no encadeamento $x$ MJ $y$, representar a persuasão relacionada àquela instrução. Para Lopes (2012, p. 461), a relação causal entre essas TDs "parece configurar uma estratégia discursiva de atenuação da relação de poder e controle do locutor sobre o interlocutor, tendente à eventual mitigação de uma atitude de resistência por parte deste último". Dessa forma, como o Juntograma deixa ver, não destacamos a repetibilidade da junção causal, como constitutiva da TD injuntiva, mas a mescla de TDs que possibilita e justifica o seu uso.

Para a produção do Texto (5), a pesquisadora solicitou às crianças que convidassem a jornalista E. a visitar a escola para falar sobre seu trabalho e combinou com elas que apenas dois convites seriam entregues em nome de toda classe: 
Texto (5)

A.

Para 30/10/02

E.

E. você poderia vir com a Cristiane a

escola ø ensinar como que se faz uma repostagem

porque a Cristiane disse para classe inteira que você

e reporter, e voce trabalha com o diario da

reigiao e voce pode vir ou não. [02/14/02]

Embora a proposta solicite a produção de um convite, nos textos resultantes, mesclam-se TDs diferentes, com destaque para a TD pedido, conforme (5). Da TD convite, propriamente dita, observamos apenas a apresentação do remetente $(A$.), do destinatário (Para E.), da data $(30 / 10 / 02)$ e do vocativo (E.). A presença de verbos no futuro do pretérito do indicativo é recorrente, nas TDs convite e pedido, uma vez que expressa o desejo do sujeito que convida/pede (E. você poderia vir com a C. a escola).

$\mathrm{Na}$ TD pedido, o sujeito expressa um desejo, uma vontade, solicita algo a alguém. Em textos dessa tradição, as expressões clamativas (por favor) são recorrentes. Outra característica dessa tradição é que, após o pedido, é comum que o sujeito acrescente uma TD explicativa, com o motivo pelo qual está convidando ou pedindo algo, com a validação de seu desejo, e/ou uma TD argumentativa, com a representação persuasiva do leitor, a fim de que realize o que lhe foi solicitado. Essas tradições esclarecem, ao destinatário, os motivos que levaram ao convite/ pedido e, assim, criam a orientação argumentativa de convencimento.

O Juntograma (5) destaca os MJs que ocorrem no Texto (5):

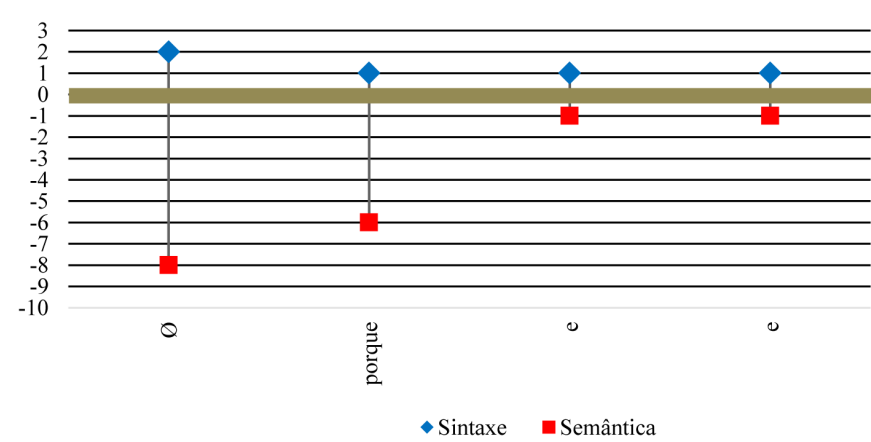

\begin{tabular}{|l|}
\hline Legenda \\
Sintaxe \\
$1=$ parataxe \\
$2=$ hipotaxe \\
Semântica \\
$-1=$ adição \\
$-2=$ alternância \\
$-3=$ modo \\
$-4=$ comparação \\
$-5=$ tempo \\
$-6=$ causa \\
$-7=$ condição \\
$-8=$ finalidade \\
$-9=$ contraste \\
$-10=$ concessão \\
\end{tabular}

Juntograma 5: Mapeamento dos MJs nas TDs convite/pedido - Texto (5) [02/14/02].

Embora as ocorrências de MJs sejam reduzidas, são representativas da mescla de TDs constatada no texto analisado, a exemplo de outros. A justaposição, em " $E$. você poderia vir com a C. a escola ensinar como que se faz uma repostagem", 
evidencia a finalidade do que é pedido, numa estreita ligação entre as orações que constituem o complexo. Na sequência, o MJ causal encabeça uma justificativa/ explicação para o pedido, expresso no primeiro segmento, "porque a $C$. disse para classe inteira que você e reporter, e voce trabalha com o diario da reigiao". Assim, como no Juntograma (4), também neste não é a repetibilidade do MJ, no mesmo texto, que permite estabelecer uma relação entre as TDs e a causalidade, mas sim o momento específico, no texto, em que o sujeito atrela o pedido à explicação/ argumentação.

\section{CONSIDERAÇÕES FINAIS}

Com o objetivo de investigar a relação entre a TD e o uso dos MJs - com destaque para os causais - e, consequentemente, o modo como esses mecanismos podem ser tomados como indícios de determinadas TDs, visualizamos, a partir de Juntogramas, a disposição e a frequência dos MJs nas tradições investigadas.

Os resultados evidenciam dois tipos de relações possíveis entre esses MJs e as TDs focalizadas: (i) com as TDs narração, relato, argumentativa e explicativa, em que a repetibilidade dos espaços de junção preenchidos por mecanismos com acepção causal reafirma a hipótese que caracteriza o aspecto sintomático entre a TD que se constitui e a forma como os encadeamentos dessa natureza a constituem; e (ii) com as TDs cartão de Natal, injuntiva e pedido, em que o uso dos MJs causais está relacionado à mescla de TDs, diretamente associada à parte do texto em que são inseridas TDs explicativas/argumentativas. Por isso, nessas TDs, a repetibilidade dos MJs causais não pode ser o ponto de partida da análise, mas, sim, o seu papel pragmático-discursivo como matéria que constitui a composicionalidade da tradição textual.

Esses resultados mostram que, direcionado pela composicionalidade das TDs, o sujeito, ao escolher o conjunto de juntores, transita pelo que é fixo e lacunar na tradição. Atrelando esse "trânsito do sujeito" ao contexto particular de sua aquisição da escrita, vemos que, gradualmente, apreende as propriedades fixadas e variáveis das TDs; o que apresentam como evocação do já-dito, em estreito compasso com a historicidade e a experiência (memória), no sentido do já sabido dessas relações, e o que apresentam como evocação de um projeto de dizer, relacionado ao acontecimento (produto discursivo), enquanto novidade que se dá no modo como experimentam aquela prática.

Dessa forma, os MJs são observados "no espaço" em que ocorrem, sendo que essa noção de espaço recobre a dimensão sintática da língua e, concomitantemente, a enunciativa. A sintaxe é tomada, pois, como dimensão de contato entre a virtualidade do sistema e sua realização. Então, por estar em aquisição do modo escrito de enunciar, especialmente por meio daquilo que reconhece como tradicional, o sujeito lida com o fixo e lacunar, lançando mão do modo de 
enunciação que domina, o falado, via práticas de oralidade, demonstrando, assim, a heterogeneidade constitutiva da escrita. ${ }^{14}$

$\mathrm{Na}$ esteira de Abaurre et al. (2002), não estamos, com isso, defendendo um caminho direto "do falado/oral para o escrito/letrado", mas frisando o papel das tradições da oralidade, que a criança domina, em sua aquisição da escrita, somado, ainda, ao papel das tradições que estão ligadas à imagem de escrita passada pela escola e à sua natureza heterogênea.

Teoricamente, os resultados apontam consequências de um ponto próprio de observação de TDs, como matéria e produto de linguagem, a partir da investigação da constituição de práticas discursivas, tomadas como tradicionais, que parte da ideia de que os elementos juntivos do texto, considerados em espaços determinados, na qualidade de espaços de repetibilidade, são sintomas de diferentes TDs, bem como da composicionalidade de uma TD.

De forma aplicada, os resultados mostram como a heterogeneidade se constitui, nos espaços de junção, e, assim, abrem uma discussão relacionada ao ensino da escrita na escola, a partir da hipótese de que as TDs têm feito parte dos aspectos "ocultos" do letramento acadêmico (STREET, 2009), expressão que o autor utiliza para mostrar que certos aspectos da produção do texto, cobrados no momento da avaliação, não são explicitados no processo de ensino e aprendizagem.

\section{REFERÊNCIAS}

ABAURRE, M. B. M.; FIAD, R. S.; MAYRINK-SABINSON, M. L. T. Cenas de Aquisição de escrita: o sujeito e o trabalho com o texto. São Paulo: Mercado de Letras, 2002.

ASCHENBERG, H. Historische Textsortenlinguistik. Beobachtungen und Gedanken. In: DRESCHER, M. Textsorten in romanischen Sprachvergleich. Tubingen: Stauffenburg Verlag. S. 153-170, 2002.

BAKHTIN, M.; VOLOCHINOV, V. N. Marxismo e filosofia da linguagem (1929). Trad. Michel Lahud; Yara Frateschi Vieira. 7. Ed. São Paulo: Hucitec, 1995.

CAMPOS, C. M. Efeitos argumentativos na escrita infantil ou a ilusão da argumentação. Campinas. 218f. Tese de doutorado - Universidade Estadual de Campinas, Instituto de Estudos da Linguagem, 2005.

CAPRISTANO, C. C. Mudança na trajetória da criança em direção à palavra escrita. Tese (doutorado) - Universidade Estadual de Campinas. Campinas, SP: [s.n.], 2007.

CORRÊA, M. L. G. O modo heterogêneo de constituição da escrita. São Paulo: Martins Fontes, 2004.

COSERIU, E. O homem e sua linguagem. Rio de Janeiro, Presença, 1982.

${ }^{14} \mathrm{O}$ uso frequente do $\mathrm{MJ} e$ e da justaposição para a marcação da causalidade exemplifica, na prática, o fato de o sujeito recorrer àquilo que representa o que é fixo, em suas práticas de oralidade e letramento. O lacunar fica a cargo das formas de codificação da relação causal na construção das distintas tradições. 
COSERIU, E. Lições de linguística geral (edição revista e corrigida pelo autor). Rio de Janeiro: Ao livro técnico, 1980.

COSTA E SOUSA, O. Emergência e desenvolvimento da relação de causalidade em narrativas de crianças. Filologia e Linguística Portuguesa, n. 12(1), p. 91-104, 2010.

DUCROT, O. Princípios de Semântica Lingüistica (dizer e não dizer). São Paulo: Cultrix, 1977. Tradução de Carlos Vogt, Rodolfo Ilari e Rosa Attié Figueira.

GUIMARÃES, E. Texto e Argumentação. 2a ed. Campinas: Pontes, 2001 [1987].

KABATEK, J. Sobre a historicidade dos textos. Linha d'água 17, p. 157-170, 2006.

KABATEK, J. Tradiciones discursivas y cambio lingüístico. Lexis XXIX. 2, [S.1.], p. 151-177, 2005.

KOCH, I. G. V. Interferências da oralidade na aquisição da escrita. Trabalhos em Linguística Aplicada. Campinas, p. 31-38, 1997.

$\mathrm{KOCH}, \mathrm{P}$. Tradiciones discusivas y cambio lingüístico: el exemplo del tratamiento vuestra merced em español, In: KABATEK, J. (ed.). Sintaxis histórica del español y cambio lingüistico: nuevas perspectivas desde las Tradiciones Discursivas. Madrid, Iberoamericana, 2008.

LONGHIN-THOMAZI, S. R. Aquisição de Tradições Discursivas: marcas de uma escrita heterogeneamente constituída. Alfa. São Paulo, p. 225-248, 2011.

LOPES, A. C. M. Contributos para uma análise semântico-pragmática das causais de enunciação no Português europeu contemporâneo. Alfa, São Paulo, 56(2), p. 451-468, 2012.

LOPES-DAMASIO, L. R. SILVA. P. C. S. Causa em aquisição da escrita: processos juntivos. Cadernos de Letras UFF, Niterói, v. 27, n. 55, p. 109-133, 2017.

OESTERREICHER, W. Zur Fundierung von Diskurstraditionen. In: FRANK, B; HAYE, T.; TOPHINKE, D. (Orgs.): ScriptaOralia. Tübingen, 1997.

RAIBLE, W. Linking clauses. In: HASPELMATH, M. et al. (Ed). Language typology and language universals: an international handbook. Berlin: Walter de Gruyter, 2001. p. 590-617.

STREET, B. Perspectivas interculturais sobre o letramento. Filologia e linguistica portuguesa. São Paulo: Humanistas/FFLCH/USP, v. 8, p. 465-488, 2006.

VEYNE, P. Comment on écrit l'histoire (suivi de: Foucault révolutionne l'histoire). Paris: Seuil, 1971.

ZIV, Y. Causality and context dependence. Belgian Journal of linguistics, v. 8: p.187-200, 1993. 